\title{
Biomedicine Miniaturization Forum to be Held in April 2005
}

The ASME Nanotechnology Institute announces Biomedicine Miniaturization 2005: 3rd Nano Growth OpportunitiesBiotech \& Medical Device Sectors Impact Forum, to be held April 7-8, 2005, at the Hilton Irvine Orange County Airport Hotel in Irvine, Calif. The goal of the forum is to discuss how biotechnology and biomedical device sectors can benefit from nanotechnology and to explore nanotechnology solutions that will help transform healthcare.

Among the topics are "Nanoparticulate Optical Quantitation Tags Based on Surface-Enhanced Raman Scattering (SERS)," to be presented by Michael Natan (Nanoplex Technologies Inc.) and "Next-Generation Microfluidic Ink
Delivery Systems for Dip-Pen Nanolithography (DPN ${ }^{\mathrm{TM}}$ ) Applications in Biotechnology," to be presented by Debjyoti Banerjee (Applied Biosystems). The forum includes a panel on Industry ViewpointFuture Directions. The program builds on the 2004 Nanotechnology Growth Opportunities for the Biotech and Medical Device Sectors Impact Forum, which attracted engineers, researchers, business, legal, and finance professionals from Nanotrope, Medtronic, NASA Ames Research Center, Nanosciences, AMI Semiconductor, Bioforce Nanosciences, Pacific Growth Strategy, Pillsbury Winthrop, Applied Micro Structures, Allergan, Scripps Research Institute, Tektronix, and Versant Ventures, among others.
ASME's 3rd Bioengineering Technology Seminar will precede the forum on April 5-6. The solutions-oriented short courses, offered by ASME's Continuing Education Institute, will include Biomaterials in the Design of Medical Devices and Bionanotechnology: The Use of Nanotechnology for Biomedical Applications, among other topics.

Biomedicine Miniaturization 2005 is endorsed by the Materials Research Society, the Society for Biomaterials, and the Biomaterials Network.

For further information, access Web site www.asmeconferences.org/nanobio05 or contact nano@asme.org or Brandy Smith at smithb@asme.org.

\section{9th International Symposium on Metallomesogens ISM-2005 to be Held June 2005}

The 9th International Symposium on Metallomesogens ISM-2005 will be held May 31 to June 3, 2005, at the Lake Arrowhead UCLA Conference Center, nestled in the San Bernardino mountains east of Los Angeles. The scope of this year's conference has been broadened in order to foster scientific interchanges among those scientists who have traditionally been interested in metallomesogens and those interested in other types of soft materials that contain metals. This meeting should attract scientists with interests in inorganic, coordination, organic, organometallic, and physical chemistry as well as physics and biology, with the goal of promoting new synergism across disparate fields. The goal of the conference is to foster connections between scientists with expertise in metallomesogens and those who are working with gels, dendrimers, membranes, and other metal-containing soft materials.

Plenary speakers for the conference include well-known experts in many areas of liquid-crystal research and related fields. Among the speakers are Duncan Bruce, University of Exeter, U.K.; Akira Mori, Kyushu University, Japan; Claude Piguet, University of Geneva, Switzerland; John Seddon, Imperial College London, U.K.; Jadwiga Szydlowska, University of Warsaw, Poland; Hideo Takezoe, Tokyo Institute of Technology, Japan; and Stuart Rowan, Case Western University, U.S.

The chair of the organizing committee is Gerald Van Hecke of Harvey Mudd College. Co-chairs are Robert Bachman
(University of the South), Lee Park (Williams College), and Eric Scharrer (University of Puget Sound). The conference is endorsed by the Materials Research Society.

Details concerning registration, accommodation, and travel arrangements can be found on the conference Web site at www.sewanee.edu/rbachman/ism05.htm. Late registrations through April 30 are being handled on a first-come, firstserved basis. Limited financial support for undergraduate, graduate, and postdoctoral participants may become available; interested parties should contact members of the organizing committee for further information.

\section{Fall Meeting F06 Request for Symposium Proposals}

November 27 - December 1

Exhibit: November 28 - 30

Boston, MA
The Chairs for the 2006 Fall Meeting are accepting symposium proposals through March 31, 2005.

Proposals should include a description of the suggested topic, the names and affiliations of probable symposium organizers, and comments about the topic's importance to the materials science community as well as its history, if any, at previous MRS events.

We invite you to view additional detail about preparing a symposium proposal.

\section{Meeting Chairs}

$\begin{array}{lll}\text { Ralph G. Nuzzo } & \text { Louis J. Terminello } & \text { Helena Van Swygenhoven } \\ \text { University of Illinois, Urbana-Champaign } & \text { Lawrence Livermore National Laboratory } & \text { Paul Scherrer Institute } \\ \text { Frederick Seitz Materials Research } & \text { MS L-125 } & \text { NUM/ASQ } \\ \text { Laboratory } & \text { P.O. Box } 808 & \text { WHGA/343 } \\ \text { 104 S. Goodwin Avenue } & \text { Livermore, CA 94551 } & \text { CH-5232 Villigen } \\ \text { Urbana, IL 61801 } & \text { Tel: 925-423-7956 } & \text { Switzerland } \\ \text { Tel: 217-333-1370 } & \text { Fax: 925-422-0029 } & \text { Tel: 41-56-310-2931 } \\ \text { Fax: 217-244-2278 } & \text { Email: terminello1@llnl.gov } & \text { Fax: 41-56-310-3131 } \\ \text { Email: r-nuzzo@uiuc.edu } & & \end{array}$

Babu R. Chalamala Indocel Technologies, Inc P.O. Box 12238

Research Triangle Park, NC 27709

Tel: $\quad 919-244-1040$

Fax: $\quad 888-853-4407$

Email: chalamala@indocel.net 